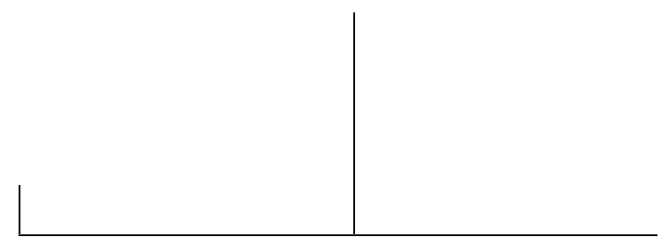

Rev. Latinoam. Psicopat. Fund., São Paulo, 16(1), 100-115, mar. 2013

\title{
Balizamentos éticos para o trabalho em saúde mental: uma leitura psicanalítica*
}

\author{
Lilian Miranda \\ Rosana Teresa Onocko Campos
}

\begin{abstract}
Propõe-se uma reflexão teórica sobre balizamentos éticos para a prática clínica nos serviços substitutivos de saúde mental e apresentam-se conceitos da psicanálise freudiana e winnicottiana, discutindo-os à luz de depoimentos de sujeitos com diagnóstico de psicose. Ressalta-se a necessidade de que os profissionais sustentem uma posição paradoxal, marcada pela presença implicada na relação com seus pacientes e a suspensão de seus próprios desejos, posição esta que requer a existência de espaços coletivos no serviço, propiciando apoio e análise das relações intersubjetivas.
\end{abstract}

Palavras-chave: Saúde mental, ética, psicanálise, Winnicott

*Artigo baseado em pesquisa de doutorado "Transitando entre o coletivo e individual: reflexões sobre o trabalho de referência junto a pacientes psicóticos". Tese apresentada em 19 de junho de 2009 no Departamento de Medicina Preventiva e Social. Faculdade de Ciências Médicas. Unicamp (Campinas, SP, Br).

Auxílio financeiro concedido pelo Conselho Nacional de Desenvolvimento Científico e Tecnológico - CNPq (Brasília, DF, Br), Processo 554426/2005-06 AI e pela Capes Coordenação de Aperfeiçoamento de Pessoal de Nivel Superior (Brasília, DF, Br) (bolsa de doutorado). 


\section{Introdução}

Influenciadas pelo Movimento da Reforma Psiquiátrica, as políticas públicas brasileiras de saúde mental vêm investindo na estruturação de serviços que objetivam não apenas o alívio do sofrimento de seus usuários, como também ganhos nas esferas da inserção social e das possibilidades de cuidado de si. Dentre eles, destacam-se os Centros de Atenção Psicossocial - CAPS, instituições que têm se mostrado eficazes no processo de desospitalização e acolhimento dos pacientes psicóticos, favorecendo o trabalho subjetivo dos mesmos (Kantorski et al., 2009; Onocko Campos et al., 2009).

Alguns autores reconhecem a importância dos CAPS, mas diante da abrangência de ações que eles envolvem, associada ao excesso e à diversidade de demandas, têm discutido o risco de que reproduzam práticas tutelares e controladoras, ainda que desenvolvidas em espaços regidos por princípios reformistas. Apontam, ainda, grande carga de sofrimento psíquico nos profissionais, que muitas vezes expressam atitudes que oscilam entre perigosa onipotência e devastadora impotência (Sampaio et al., 2011; Miranda \& Onocko Campos, 2010). Entre os fatores associados a esse quadro, destacam a intensidade da responsabilização que os técnicos assumem sobre os projetos terapêuticos de seus pacientes e a insuficiência de espaços de supervisão clínico-institucional (Silva \& Costa, 2010).

Parece-nos que um trabalho pautado por intensas relações interpessoais, próprio aos CAPS, envolve a necessidade de que os profissionais lidem com suas manifestações afetivas, que podem se caracterizar como defesas ligadas à onipotência, somatização, idealização, dentre tantas outras demasiado humanas (Onocko Cam- 
pos, 2005). Espera-se, entretanto, que sustentem um posicionamento e uma prática balizados pelos princípios ligados à construção epistemológica, teórica, política e cultural da Reforma Psiquiátrica (Amarante, 2007), à técnica aprendida nos diversos campos disciplinares que compõem a saúde mental, mas, principalmente, a uma questão ética.

Objetivando contribuir com a reflexão acerca de certos balizamentos éticos, voltados aos trabalhadores de saúde mental, este é um estudo teórico que traz reflexões desenvolvidas a partir da psicanálise, principalmente na sua leitura winnicottiana, dialogando-as com alguns depoimentos de pacientes de CAPS, entrevistados pelas autoras.

Tais entrevistas advêm de uma pesquisa qualitativa, cujo objetivo foi investigar o trabalho dos técnicos e equipes de referência nos CAPS e discuti-lo à luz de tradições teóricas da saúde coletiva, saúde mental e psicanálise. Para realizá-las, adotou-se um roteiro de questões semidirigidas que abrangiam temas relacionados às experiências significativas de vida do paciente, sua relação com os profissionais do CAPS e a avaliação que fazem do tratamento. Os pacientes entrevistados tinham o diagnóstico de psicose, segundo a equipe que os acompanhava. Não detalharemos neste trabalho todo o conteúdo das entrevistas porque sua apresentação será circunscrita às possibilidades de diálogo com a temática da ética em saúde mental.

Vale esclarecer que a pesquisa foi aprovada pelo Comitê de Ética da Faculdade de Ciências Médicas da Unicamp (Parecer 396/2004) e todos os participantes assinaram termo de consentimento livre esclarecido, condizente com as diretrizes e normas da Resolução 196/1996 do Conselho Nacional de Saúde e da Resolução n. 251, de 7/8/1997, do mesmo conselho, atendendo as exigências da Declaração de Helsinki.

\section{A ética como morada e seu processo de constituição}

Ao discutir a estruturação de serviços de saúde mental, Goldberg (1996) defende que estes requerem um trabalho interdisciplinar, capaz de produzir um cotidiano institucional repleto de projetos, atividades e vivências, de tal modo que cada paciente seja tratado através de uma abordagem pessoal, podendo perceber a seriedade com que suas falas e gestos são acolhidos. A psicanálise é apenas um dos vários saberes que podem compor esse campo, cujas práticas costumam ser distintas daquilo que ficou conhecido como setting psicanalítico tradicional.

Consideramos, entretanto, que algumas reflexões sobre a ética da psicanálise podem orientar um posicionamento clínico do profissional em variados dis- 
positivos, tais como práticas grupais, acompanhamentos terapêuticos, oficinas de trabalho, dentre outros. Sendo assim, passamos a discutir alguns elementos da ética psicanalítica que, embora originalmente desenvolvidos no âmbito de uma perspectiva de tratamento analítico stricto sensu, podem contribuir para o balizamento ético de várias práticas em saúde mental.

Figueiredo (1996) aponta que, a despeito da polissemia do termo ética, podemos remontá-lo a uma de suas raízes etimológicas, associando-o não apenas a noções como costumes e hábitos, mas também à ideia de “(...) morada coletiva [o que nos leva a] ver nele - nos valores, nas posturas, nos costumes e hábitos - algo equivalente à morada de onde podemos contemplar, a uma certa distância, as coisas lá fora" (pp. 69-70, grifo do autor). Para ele, um "habitar sereno e confiado" é condição para a manutenção de alguma diferenciação entre eu e outro, bem como para o desenvolvimento da capacidade de pensar, representar, brincar e experimentar o próprio corpo.

Baseando-se em estudiosos da psicologia do self, Figueiredo (1996) lembra que nossas primeiras experiências de morada se realizam na relação de identificação com a mãe, quando ainda somos bebês. Essa relação nos permite o desenvolvimento de certa morada interna para onde podemos recorrer e, a partir de onde, fazemos o trânsito com a realidade externa. Já a vivência social mais ampla nos leva a construções de moradas simbólicas e coletivas, que instituem uma troca regulada de afetos e obrigações recíprocas.

Trata-se, portanto, da ideia de ética enquanto um lugar a partir do qual se desenvolve a fala para o outro e a escuta dele. Nesse sentido, a ética seria o grande sustentáculo da clínica psicanalítica, pois determina seu compromisso "(...) com a escuta do interdito e com a sustentação de tensões e conflitos (...)" (Figueiredo, 1996, p. 63). A nosso ver, esse posicionamento aberto à alteridade e à sustentação das tensões é consonante com o compromisso ético que a Reforma Psiquiátrica faz em relação à luta pelo direito de que o louco ocupe os diversos espaços sociais e possa nele interferir como cidadão, de tal modo que se constitua um enfrentamento democrático dos conflitos entre expressões subjetivas diferentes ou interesses sociopolíticos contrastantes.

O desenvolvimento da consideração pelo outro é estudado por Winnicott (1958) a partir do que ele denomina "capacidade para preocupar-se" ou "concernimento". Tal capacidade é conquistada quando a criança, tendo passado suficientemente bem por um processo de dependência absoluta da mãe, já alcançou a integração egoica necessária para perceber e conter seus impulsos amorosos e agressivos, bem como para suportar o fato de que a mãe provedora é a mesma que frustra e decepciona. Nesse momento, ela faz aproximações agressivas em direção à mãe, já percebida como um não eu, mas também se sente 
impelida a construir reparações no objeto agredido. A sobrevivência da mãe aos ataques (que não significa submissão a eles) e sua aceitação dos movimentos reparadores, capacita a criança para suportar a ambivalência de seus sentimentos e a se sentir responsável por eles, tanto em seus aspectos amorosos como agressivos. Consequentemente, consegue desenvolver a capacidade para se preocupar com o objeto simultaneamente amado e odiado.

Já a conformação de um plano ético comum, ou de uma morada coletiva, que media as interações sociais, nos remete à vivência edípica. Através da obra freudiana, Vollmer Filho \& Berlim (2005) apontam que a psicogênese do sentimento de ética está baseada na introjeção da figura paterna, via identificação, e no desenvolvimento da capacidade de consideração pelo outro, permitindo que a lei do pai deixe de ser uma pressão exterior, para se tornar uma proibição interiorizada. Entretanto, tal interiorização se faz à custa da vivência de um conflito que, inevitavelmente, coloca-se como um dilema ético, polarizado entre a onipotência pulsional e a consciência da castração, que nos conduz à consideração pelo outro e sua força.

Nessa perspectiva, a interpretação freudiana acerca do mito do assassinato do pai primevo deixa clara a ambivalência envolvida na relação dos filhos com o pai. Se, num primeiro momento, o ódio prevaleceu, desencadeando o parricídio, logo em seguida ressurgiram os sentimentos amorosos. Estes foram intensificados pela frustração, decorrente do fato de que nenhum dos irmãos pôde ocupar o lugar do pai, e pela culpa e o remorso, responsáveis pelos sentimentos de exaltação da figura paterna (Vollmer Filho \& Berlim, 2005).

Ao tratar do tema do Planejamento em saúde e propor alguns balizamentos éticos para a estruturação das instituições, Onocko Campos (2003) se remete à leitura que Cornélio Castoriadis e René Kaës fazem da teoria freudiana e destaca outro aspecto constitutivo da experiência do parricídio e da psicogênese do sentimento de ética: a fraternidade. Por intermédio de Castoriadis (1986), a autora ressalta a escolha dos irmãos por compor um pacto fraterno. Este, uma vez coletivamente construído, mostrou-se comprometido com o impedimento da concentração, num só indivíduo, do exercício absoluto do poder, o que culmina no “(...) direito a ter desejos de uma vida institucional mais justa e fraterna, na procura de uma democracia (...)" (Onocko Campos, 2001b, p. 151).

Nesse sentido, poderíamos remontar a ideia de ética como morada coleti$v a$ e pensá-la enquanto uma escolha humana a favor de uma união entre vários, a qual, sem perder seu caráter ambivalente e conflituoso, pode se mostrar forte para construir espaços acolhedores das diversificadas existências humanas. 


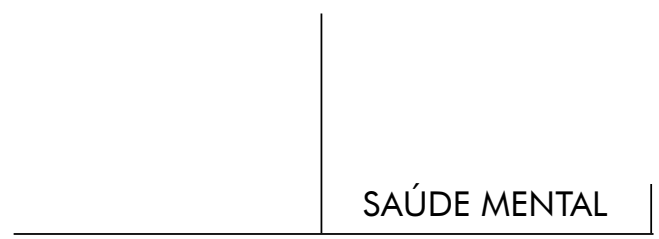

\section{Discussão sobre ética no campo da prática clínica}

Ao trazer a discussão sobre ética para o campo da prática clínica, entende-se que, desde Freud, o método psicanalítico e a ética compõem um campo de constituição mútua e contínua (Junqueira \& Coelho Jr., 2005). Freud (1912/1996) propõe que a ética do analista consiste no amor à verdade do paciente e na sua honestidade para com os próprios desejos e impulsos. Assim, ao tratar da etiologia dos delírios, ele afirma: “(...) acontece que existe uma parcela de verdade oculta em todo delírio, um elemento digno de fé, que é a origem da convicção do paciente, a qual, portanto, até certo ponto é justificada" (p. 74).

Cabe ao terapeuta, através de sua psicanálise pessoal, conhecer suas próprias referências para saber colocá-las em suspenso durante o contato com o paciente. Para tanto, Freud (1912/1996) sugere o uso da atenção uniformemente flutuante, a qual, conforme comentam Figueiredo \& Coelho Jr. (2008), impede um tipo de escuta pretensamente totalitária.

Freud (1913/1996) orienta que o psicanalista se abstenha de juízos de valor ou julgamentos morais, assim como de revelações precipitadas acerca dos sintomas do paciente. Lembra ainda que cada processo analítico tem seu ritmo, o que deve conter a ansiedade de cura tanto do paciente quanto do analista. Em outro trabalho, ressalta: “(...) Via de regra, adiamos falar-lhe [ao paciente] de uma construção ou explicação até que ele próprio tenha chegado, de fato, à síntese decisiva. Se procedemos doutra maneira e o esmagamos com nossas interpretações (...), nossa informação ou não produziria efeito algum ou, então, provocaria uma violenta irrupção de resistência (...)" (Freud, 1938/1996, p. 192). Portanto, cabe ao psicanalista manter apenas uma "simpatia compreensiva"1 (Freud, 1913/1996, p. 154) para com o analisando, permitindo que, com o tempo, este desenvolva sua transferência, através da qual atualizará os conflitos e poderá elaborá-los.

Entendemos que essa postura de abstenção de juízos e expectativas pode ser útil para diferentes profissionais, mesmo que não estejam na posição de psicanalista do paciente. No trecho que segue, uma paciente nos relata uma situação em que procura um hospital porque sentia dores na barriga e é reencaminhada para o CAPS porque se revolta com o procedimento a que tentam

${ }^{1}$ Esta expressão, presente na tradução brasileira do texto freudiano, conforme referência bibliográfica,deve remeter-nos a um posicionamento que se abstém de julgamentos ou expectativas para com o analisando. Não se trata, portanto, de indulgência, boa vontade ou complacência, mas sim de disposição para ouvir o outro em sua alteridade, respeitando seu próprio ritmo de associações e elaborações. 
submetê-la, sem antes ouvirem a origem de sua dor (relacionada a uma vivência delirante). Seu comentário diante dessa situação evidencia a importância de que o posicionamento ético seja mantido pelos profissionais nos diferentes contextos e situações que envolvem o tratamento: Se eu chego no médico e conto que estou cheia de gases e sofri um atentado terrorista, ele não acredita. Mas, a minha referência sabe que eu estou falando a verdade. Então fica mais fácil, porque ela sabe que não é coisa da minha cabeça, que não é mentira minha. Ela me conhece e acredita em mim.

Baseando-se na leitura freudiana, Figueiredo e Coelho Jr. (2008) ajudam-nos a discutir a necessidade de respeito às construções do paciente, lembrando que a psicanálise não “(...) é uma imposição ortopédica de novas formas para corrigir formas antigas e defeituosas (...)" (p. 21), estando interditado o uso abusivo da sugestão, calcado na ideia de que a teoria e a experiência podem capacitar o terapeuta a saber o que é bom para o outro. Um dos sujeitos entrevistados na nossa pesquisa dá mostras da importância dessas condições éticas, afirmando que é necessário que os profissionais respeitem (...) a verdade do paciente e não saiam por aí dando sentenças, acusando-o de estar delirando (...). Note-se que essa advertência deve valer para todos os profissionais do serviço, independentemente da posição que ocupem no tratamento de cada paciente.

Na mesma direção, ao pesquisar o processo de restabelecimento de pacientes psicóticos, Corin (2002) pontua:

$\mathrm{O}$ que ajuda as pessoas a permanecer na comunidade parece ser a possibilidade de construir um espaço, ao mesmo tempo, dentro e fora, um mundo um pouco retraído onde elas possam se comunicar com elas mesmas e caminhar segundo seu próprio ritmo. (...) Tratar da questão da reinserção das pessoas psicóticas implica a necessidade de segui-las nas suas narrativas, nos seus trajetos, nos seus silêncios. É necessário também mudar a ordem de prioridades: procurar compreender como as pessoas procuram se restabelecer e reencontrar um lugar no mundo social e cultural de acordo com um ritmo e uma modalidade que lhes são próprios (...) (p. 69; tradução nossa)

A autora adverte para a necessidade de evitarmos tentativas de adaptação dos usuários ao nosso mundo ordinário, incutindo-lhes métodos educativos de aprendizagem de habilidades, com o objetivo de modificar seus esquemas representacionais.

Nosso material empírico aponta para a valorização que os pacientes fazem dessa espécie de discrição ou abstinência do analista, mas também indica que eles atribuem uma grande importância aos contatos vivos ou mais afetivos com seus terapeutas. Assim, um de nossos entrevistados exemplifica: as minhas referências me passam uma energia boa. Sinto que eles gostam de mim (...) Isso é bom para 


\section{SAÚDE MENTAL}

mim, sinto uma força. (...) Na minha vida passada eu nunca havia sentido que as pessoas gostavam de mim.

Por outro lado, nossas entrevistas indicam alguns dilemas éticos, representados quando os pacientes afirmam, por exemplo, que lhes é importante o fato de o profissional dizer o que podem fazer, cuidar de seus benefícios, mostrar preocupação com suas vidas, dar conselhos, ou: (...) ficar sempre de olho para ver se o paciente não erra.

A nosso ver, esse tipo de situação nos coloca diante de um conflito marcado pela delicada tensão entre cuidado e tutela, atenção constante e controle, proximidade afetiva e objetificação do outro. Para lidar com essas tensões, parecem-nos válidas algumas elaborações, feitas por Figueiredo e Coelho Jr. (2008), que propõem um tipo de posicionamento paradoxal do terapeuta, representado pelo binômio "presença implicada-reserva". Os autores sugerem que o analista sustente uma presença que comporta certa ausência. Trata-se de uma reserva de si para o outro, que permite que o paciente surpreenda ao analista com suas associações livres, recordações, repetições, respostas transferenciais e acting out. Ao colocar-se em reserva, o analista fica confinado às "suas reservas anímicas e corporais" (p. 26), o que livra sua escuta das censuras e controles impostos pela consciência.

Note-se que o termo reserva está sendo tomado em duas acepções: aquela que diz respeito à discrição e aquela que se refere a uma parte de material que fica guardada, reservada. Assim, ao colocar-se em reserva, o analista está, ao mesmo tempo, ocupando um lugar de discrição e reservando capacidade psíquica para suportar as turbulências do processo analítico.

Baseando-se em autores da escola inglesa de psicanálise, Figueiredo e Coelho Jr. (2008) sugerem que o analista possa estar presente no campo analítico para, progressivamente, ausentar-se. Ao fazê-lo, ele está possibilitando tanto a si, como ao paciente, o contato com aquela parte da experiência subjetiva que não é passível de compartilhamento e que serve como uma espécie de reserva do "si mesmo de cada um". No entanto, a ausência progressiva depende da capacidade de estar presente e disponível para ser usado pelo paciente, tal como este precise. Essa capacidade consiste na dimensão de implicação da presença, essencial para que se conheça o outro e lhe permita a sensação de ser acolhido. Trata-se, portanto, de um posicionamento que guarda um paradoxo sinalizador da importância da manutenção constante da dialética presença implicada-reserva.

A teoria, a supervisão, as escolas de psicanálise e a análise pessoal são formas de reserva que devem contribuir para que o profissional sinta-se nutrido para preservar sua presença implicada na relação terapêutica. Ao mesmo tempo, respeitando a inevitável condição paradoxal desse posicionamento, as reservas devem ajudá-lo a se ausentar, colocar-se em suspenso, evitando intrusões e 
permitindo que o paciente, no seu ritmo, viva suas questões emocionais e crie seu percurso de tratamento.

Uma paciente entrevistada nos mostra o quão paradoxal é sua relação com o serviço onde se trata: $O$ CAPS para mim tem duas fases boas. Uma ruim e uma má. Não tenho o que reclamar dos funcionários, nem da enfermagem (...) A enfermagem não acreditava em mim quando eu dizia que estavam me torturando com injeção. Acreditava apenas no médico. Foi preciso eu amaldiçoar o médico, para que as pessoas acreditassem em mim. Mas, a alegria do CAPS é contagiante. Os pacientes, até o guarda, formam uma grande família para mim. Eu sei que o médico me envenenou porque eu vomitei o veneno (...). Falas como essas parecem indicar o pedido que os pacientes fazem para que os profissionais se ausentem, permitindo-lhes viver suas ambivalências e produções delirantes, mas que, ao mesmo tempo, preservem um clima familiar, em que as presenças são sentidas. Note-se, porém, que essa familiaridade diz respeito à sensação de que o serviço possui dispositivos acolhedores da diferença, da contradição e do sofrimento extremado, o que exige a manutenção do paradoxo representado pela presença implicada, que acolhe o sujeito, e a reserva, que lhe garante o espaço para as construções singulares.

\section{Paradoxos do posicionamento do terapeuta}

Podemos compreender melhor essas questões paradoxais pelas afirmações que Winnicott (1962) faz acerca do posicionamento do psicanalista na relação com seu paciente: “(...) ao praticar psicanálise, tenho o objetivo de: me manter vivo; me manter bem; me manter desperto. Objetivo ser eu mesmo e me portar bem. Uma vez iniciada a análise espero continuar com ela, sobreviver a ela e terminá-la" (p. 152). O autor segue sua exposição afirmando que sempre procura se comunicar com o paciente a partir da posição em que este o coloca, segundo seus movimentos transferenciais. Consequentemente, permite-se ser um objeto subjetivo do paciente, sem, no entanto, deixar de representar o princípio da realidade e manter-se atento a esta.

Na sua leitura desse trabalho winnicottiano, Figueiredo e Coelho Jr. (2008) apresentam outro paradoxo: o objetivo de ser eu mesmo nos remete a uma postura baseada na autenticidade, sinceridade e presença implicada. No entanto, o objetivo de me portar bem nos conduz à ideia de uma "(...) obediência a algumas regras, requer uma autorrestrição, uma reserva de presença do analista (...)"(p. 108, grifo dos autores). Num primeiro momento o ser eu mesmo se coloca como presença implicada, necessária para a instauração de um campo rela- 
cional vivo. Mas, num segundo momento, o analista apoia-se no seu si mesmo justamente para colocar-se numa condição de não implicação. Esta lhe permite separar-se das fantasias transferenciais e deixar o analisando consigo mesmo, evitando as intrusões.

Aprofundando suas reflexões acerca do paradoxo que sustenta a posição do analista, Winnicott (1962) afirma que ao fazer uma interpretação pode sinalizar ao paciente que não compreende tudo, o que contribui para interditar suas possíveis atitudes onipotentes. Comenta: “(...) eu retenho certa qualidade externa, por não acertar sempre no alvo ou mesmo estar errado (...)". Aproximamos essa reflexão winnicottiana com a fala de outra entrevistada, que expressa valorizar o fato de sua técnica de referência fazer orientações, mesmo que não seja o que queremos. Na sua perspectiva, essa postura possibilita que a profissional não se coloque como aquele tipo de psicóloga de antigamente, que só ficava olhando enquanto a gente falava, (...) não dizia o que achava. Ao mesmo tempo, essa entrevistada enfatiza que tal relação é possível porque há uma disponibilidade da psicóloga para certa escuta, que supomos basear-se numa postura de abstenção de valores e juízos: Ela me escuta.(...) Consegue fazer isso através da conversa e da atenção que nos dá.

Winnicott (1961) nos ajuda a discutir a tensão situada entre a valorização que os pacientes fazem do contato afetivo com os profissionais e a necessidade de que estes se abstenham de seus valores e expectativas no contexto clínico, comentando que é comum que os pacientes psicóticos pressionem “(...) muito a integridade do terapeuta, já que necessitam de contato humano e de sentimentos reais, e mesmo assim precisam colocar uma confiança absoluta na relação da qual tanto dependem" (p. 102). O autor assevera, entretanto, que essa relação não deve se confundir com uma amizade pessoal, sendo imperioso que o terapeuta se mantenha respeitando seus horários de trabalho e o pagamento que dele provém, além de ter em mente que toda psicoterapia chega a um fim.

Essa discussão representa importante contribuição teórica nos CAPS, mesmo quando aplicada a arranjos clínicos diferentes das terapias psicanalíticas, pois as "pressões sobre a integridade" dos terapeutas são intensamente experimentadas nas variadas práticas que compõem cotidiano dos serviços. Além disso, nota-se que as dificuldades dos trabalhadores para discernir a especificidade transferencial do trabalho (e, em consequência, dar limite ao seu envolvimento, evitando a sobreimplicação) são muitas vezes exacerbadas pelo componente ideológico sempre presente nesses equipamentos. Essas questões tendem a gerar sobrecarga de trabalho e sofrimento psíquico para os próprios profissionais, tal como apontam Silva e Costa (2010). 


\section{Possibilidades terapêuticas advindas da sustentação do paradoxo}

Winnicott (1955) nos permite avançar na discussão acerca do paradoxo entre sustentação da ética e manutenção de um contato pessoal com o paciente, argumentando que, depois da vivência de um processo de adaptação suficientemente boa do analista, as falhas deste podem ser úteis para a análise. Isso porque, confiante na capacidade do analista de sobreviver à sua destrutividade, o paciente pode utilizar as falhas dentro de suas vivências transferenciais, experimentando-as como se fossem a falha ocorrida no passado e responsável por uma experiência de ruptura da continuidade do ser. Como pode contar com a confiabilidade no analista, o paciente sente-se capaz de zangar-se com ele e viver a raiva decorrente do erro ocorrido. Consequentemente, não está mais submetido à ruptura, pode vivê-la e reagir a ela.

Winnicott assevera, entretanto, que esse processo exige que o analista reconheça que a falha lhe pertence e não se refere à resistência do paciente, responsabilizando-se pelo seu erro. Se recorre a atitudes defensivas, o analista subtrai do paciente a possibilidade de zangar-se com a falha passada, justamente quando a raiva poderia ser experimentada. Com essa reflexão, novamente deparamo-nos com o caráter paradoxal das intenções de ser eu mesmo e comportar-me bem: se é possível falhar, é, ao mesmo tempo, imperioso se responsabilizar pela falha, reconhecendo seu significado e utilidade para o paciente. Para o autor: “(...) é esta parte do trabalho que liberta o paciente de sua dependência ao analista" (p. 398).

A esse respeito, Vollmer Filho e Berlim (2005) advertem que o terapeuta tem o dever ético de trabalhar para que o paciente se desprenda de sua dependência e adquira graus, cada vez maiores, de autonomia. Do mesmo modo, sabemos que autores da Reforma Psiquiátrica defendem que o tratamento permita aos pacientes aumentarem, cada vez mais, seus coeficientes de autonomia (Amarante, 2007; Goldberg, 1996).

Essa questão nos leva a retomar a afirmação de Winnicott (1962) de que, uma vez iniciada a análise, deseja “(...) continuar com ela, sobreviver a ela e terminá-la (...)” (p.152). Essa prerrogativa diz respeito a várias questões que implicam no posicionamento do terapeuta. A primeira delas se relaciona com sua disponibilidade para ser destruído pelo paciente, para ter suas limitações desvendadas e sobreviver a esse processo agressivo, essencial para o desenvolvimento da capacidade de contato com tudo o que representa o outro. Além disso, cabe ao terapeuta reconhecer que o trabalho analítico deve chegar a uma conclusão, cedendo espaço para que o paciente busque outras possibilidades de crescimento pessoal. Nesse sentido, Winnicott (1961) propõe: “(...) o objetivo de toda 
terapia é chegar a um ponto em que cessa a relação profissional, porque o viver e a vida do paciente 'assumem o comando' (...)" (p. 102).

Sugerindo uma analogia desse processo com o percurso de tratamento de alguns sujeitos, consideramos que também é fundamental que os CAPS possam reconhecer que as necessidades de seus pacientes se transformam ao longo do tempo, de tal modo que eles podem precisar do serviço de formas e intensidades diferentes, assim como podem precisar de outros espaços de vida e tratamento. Suportar os movimentos de independência do paciente é essencial para que se evite a cronificação não apenas dos usuários, mas também dos seus profissionais.

Em sua entrevista, uma paciente mostra seu percurso de profunda inserção no CAPS e desejo de paulatino afastamento. É interessante notar que ela reconhece a necessidade do acompanhamento do serviço, mas pede que os profissionais reconheçam sua necessidade de trânsito entre os vários mundos que compõem sua vida, afirmando: Quem me dá muita atenção são os profissionais daqui. (...) [quando cheguei no CAPS] a S. se apresentou, conversou comigo. Depois que aconteceu tudo ela foi me ver no hospital e começou a fazer atendimento individual comigo. Também vai em casa, almoça junto comigo. Isso é muito bom. (...) No grupo de referência, nós fazemos uma roda e falamos do que acontece em nossas vidas. Não dá para falar muito porque há coisas que são particulares. (...) Geralmente, eu estou bem no grupo, porque o meu remédio, que era semanal, agora está quinzenal. Acho que no meu grupo também começarei a vir quinzenalmente, até ter alta e ser encaminhada para o Centro de Saúde. Se eu tiver alta agora, vou sentir falta da S. Prefiro esperar, pois por enquanto não posso fazer nada.

\section{Considerações finais}

O trabalho em saúde mental é mais amplo e diverso daquele desenvolvido no setting psicanalítico clássico. Entretanto, acreditamos que as reflexões aqui desenvolvidas a partir do referencial psicanalítico poderiam contribuir para os profissionais do campo da saúde mental, na medida em que ressaltam duas prerrogativas: a interdição às pretensões onipotentes de tudo saber e controlar e, simultaneamente, a necessidade de que se suporte a habitação de uma zona paradoxal, localizada num interstício entre uma presença implicada junto ao paciente e a capacidade de ausentar-se, colocando-se em reserva (Figueiredo \& Coelho Jr., 2008). Para isso é preciso suportar certa perda narcísica que ficar na reserva pode implicar. 
Para tanto, é imprescindível que o profissional possua uma espécie de morada coletiva dentro do CAPS. Além de se utilizar de suas reservas pessoais (a própria análise, capacitação técnica, apoios afetivos), deve contar com espaços coletivos, como as supervisões clínico-institucionais, as reuniões de equipe e as assembleias que envolvem todos aqueles que frequentam o serviço. Tais espaços, embora enunciem regras, limites e possibilidades, devem se configurar, sobretudo, como sustentação para o permanente trânsito entre os paradoxos contidos nas experiências que exigem a coexistência de planos coletivos e individuais, internos e externos, rigorosamente éticos e espontâneos.

\section{Referências}

Amarante, P. (2007). Saúde Mental e Atenção Psicossocial. Rio de Janeiro: Editora Fiocruz.

Castoriadis, C. (1986). A instituição imaginária da sociedade. Rio de Janeiro: Paz e Terra.

Corin, H. (2002, primavera). Se rétablir après une crise psychotique: ouvrir une voie? Retrouver sa voix? Revue Santé Mentale au Québec, Québec, XXVII(1).

Figueiredo, L. C. M. (1996). Da epistemologia à ética. In L. C. M. Figueiredo. Revisitando as psicologias: da epistemologia à ética e discursos psicológicos $\left(3^{\mathrm{a}}\right.$. ed. rev. e amp., pp. 13-102). Petrópolis, R.J: Vozes.

Figueiredo, L. C. \& Coelho Jr., N. E. (2008). Ética e técnica em psicanálise (2ª . ed. ampliada). São Paulo: Escuta.

Freud, S. (1996). Recomendações aos médicos que exercem a psicanálise. In Edição Standard Brasileira das Obras Psicológicas Completas de Sigmund Freud (v. 12, pp. 123-133). Rio de Janeiro: Imago. (Trabalho original publicado em 1912).

Freud, S. (1996). Sobre o início do tratamento. (Novas recomendações sobre a técnica da psicanálise). In Edição Standard Brasileira das Obras Psicológicas Completas de Sigmund Freud (v. 12, pp. 137-158). Rio de Janeiro: Imago. (Trabalho original publicado em 1913).

Freud, S. (1996). Esboço de psicanálise. Moisés e o monoteísmo, esboço de psicanálise e outros trabalhos. In Edição Standard Brasileira das Obras Psicológicas Completas de Sigmund Freud (v. 23, pp. 153-221). Rio de Janeiro: Imago. (Trabalho original publicado em 1940[1938]).

Goldberg, J. (1996). Reabilitação como processo. O Centro de Atenção Psicossocial. In A. Pitta, (Org.). Reabilitação Psicossocial no Brasil (pp. 33-48). São Paulo: Hucitec. Junqueira, C. \& Coelho Jr., N. E. (2005, jun.). Considerações acerca da Ética e da Consciência Moral nas obras de Freud, Klein, Hartmann e Lacan. Psychêe, São Paulo, IX(15), 105-124. 


\section{SAÚDE MENTAL}

Kantorski, L. P. et al. (2009, ago.). Satisfação dos usuários dos centros de atenção psicossocial da região Sul do Brasil. Revista de Saúde Pública, São Paulo, XLIII, supl.1, 29-35.

Miranda, L. \& Onocko Campos, R. T. (2010, jun.). Análise das equipes de referência em saúde mental: uma perspectiva de gestão da clínica. Cadernos de Saúde Públi$c a$, Rio de Janeiro, XXVI(6), 1153-1162.

Onocko Campos, R. T. (2003). O planejamento no labirinto. São Paulo: Hucitec.

Onocko Campos, R. T. (2005, jun.). O encontro trabalhador-usuário na atenção à saúde. Uma contribuição da narrativa psicanalítica ao tema do sujeito na saúde coletiva. Ciência \& Saúde Coletiva, Rio de Janeiro, X(3), 573-583.

Onocko Campos, R. T. et. al. (2009, ago.). Avaliação da rede de centros de atenção psicossocial: entre a saúde coletiva e a saúde mental. Revista de Saúde Pública, 43, supl.1, 16-22.

Sampaio, J. J. C. et al. (2011, dez.). O trabalho em serviços de saúde mental no contexto da reforma psiquiátrica: um desafio técnico, político e ético. Ciência \& Saúde Coletiva, Rio de Janeiro, XVI(12), 4685-4694.

Silva, E. A. \& Costa, I. I. (2010, dez.). O profissional de referência em Saúde Mental: das responsabilizações ao sofrimento psíquico. Revista Latinoamericana de Psicopatologia Fundamental, XIII(4), 633-647.

Vollmer Filho, G. \& Berlim, G. (2005). Ética e Psicoterapia. In C. Eizirik et. al. (Orgs.). Psicoterapia de orientação analítica: fundamentos teóricos e clínicos (pp. 385397). Porto Alegre: Artmed.

Winnicott, D. W. (1978). Formas clínicas da transferência. In Textos selecionados: da pediatria à psicanálise (pp. 393-398). Rio de Janeiro: Francisco Alves. (Trabalho original publicado em 1955).

Winnicott, D. W. (1983). A capacidade para estar só. In $O$ ambiente e os processos de maturação (pp. 31-37). Porto Alegre: Artes Médicas. (Trabalho original publicado em 1958).

Winnicott, D. W. (1983b). Os objetivos do tratamento psicanalítico. In $O$ ambiente e os processos de maturação (pp. 152-155). Porto Alegre: Artes Médicas. (Trabalho original publicado em 1962).

Winnicott, D. W. (2005). Tipos de psicoterapia. In Tudo começa em casa (4a. ed., pp. 93-104). São Paulo: Martins Fontes. (Trabalho original publicado em 1961).

\section{Resumos}

(Ethical guidelines for working in mental health: a psychoanalytic reading)

This article consists of a theoretical reflection on ethical guidelines for clinical practice in substitutive mental health services. Concepts from Freudian and 
Winnicottian psychoanalysis are also described and discussed in the light of statements made by individuals diagnosed with psychosis. The authors highlight the need for professionals to sustain a paradoxical position marked by implicit presence in the relationship with their patients and the suspension of their own desires. This position calls for the existence of spaces at clinics that foster support and analysis of intersubjective relationships.

Key words: Mental health, ethics, psychoanalysis, Winnicott

(Repères éthiques pour le travail en santé mentale: une lecture psychanalytique)

Nous proposons une réflexion théorique sur les points de repère éthiques pour la pratique clinique des services substitutifs de santé mentale et présentons des concepts de la psychanalyse freudienne et winnicottienne que nous discutons à la lumière de témoignages de personnes atteintes de psychose. Nous soulignons qu'il est nécessaire que les professionnels soutiennent une position paradoxale marquée par la présence qu'implique le rapport avec leurs patients et la suspension de leurs propres désirs, position qui exige l'existence d'espaces collectifs de travail qui permettent de soutenir et d'analyser les rapports intersubjectifs.

Mots clés: Santé mentale, éthique, psychanalyse, Winnicott

(Guías éticas para el trabajo de salud mental: una lectura psicoanalítica)

Proponemos una reflexión teórica sobre guías éticas para la práctica clínica en los servicios sustitutivos de salud mental y presentamos conceptos del psicoanálisis freudiano y winnicottiano, discutiéndolos a la luz de los testimonios de sujetos con diagnóstico de psicosis. Resáltase la necesidad de que los profesionales sostengan una posición paradojal, por una presencia implicada en la relación con sus pacientes y suspensión de sus propios deseos, posición esta que requiere la existencia de espacios colectivos en el servicio sustitutivo de salud mental, que brinde apoyo y en donde sea posible hacer el análisis de las relaciones interpersonales.

Palabras clave: Salud mental, ética, psicoanálisis, Winnicott

(Ethische Abgrenzung für die Arbeit im Bereich der geistigen Gesundheit: eine psychoanalytische Lektüre)

Hier wird eine theoretische Reflexion über ethische Abgrenzungen in der klinischen Praxis der alternativen Dienstleistungen im Bereich der geistigen Gesundheit vorgeschlagen und Konzepte der Psychoanalyse von Freud und Winnicot vorgestellt, die unter dem Licht von Berichten von mit Psychose diagnostizierten Subjekten beleuchtet werden. Es wird hervorgehoben, dass die Fachleute eine paradoxe Stellung aufrecht halten sollten, die sich durch die implizierte Gegenwart in der Beziehung mit den Patienten und der Aufhebung der eigenen Wünsche auszeichnet.

Rev. Latinoam. Psicopat. Fund., São Paulo, 16(1), 100-115, mar. 2013 
Diese Haltung erfordert kollektive Räume auf der Arbeit, welche Unterstützung und Analyse der intersubjektiven Beziehungen ermöglichen.

Schlüsselwörter: Geistige Gesundheit, Ethik, Psychoanalyse, Winnicott

Citação/Citation: Miranda, L. \& Onocko Campos, R. T. (2013, março). Balizamentos éticos para o trabalho em saúde mental: uma leitura psicanalítica. Revista Latinoamericana de Psicopatologia Fundamental, 16(1), 100-115.

Editor do artigo/Editor: Profa. Dra. Ana Cristina Costa de Figueiredo

Recebido/Received: 10.4.2012/4.10.2012 Aceito/Accepted: 22.7.2012/7.22.2012

Copyright: () 2009 Associação Universitária de Pesquisa em Psicopatologia Fundamental/ University Association for Research in Fundamental Psychopathology. Este é um artigo de livre acesso, que permite uso irrestrito, distribuição e reprodução em qualquer meio, desde que o autor e a fonte sejam citados / This is an open-access article, which permits unrestricted use, distribution, and reproduction in any medium, provided the original author and source are credited.

Financiamento/Funding: Esta pesquisa é financiada pelo Conselho Nacional de Desenvolvimento Científico e Tecnológico - CNPq (Brasília, DF, Br) e pela Capes - Coordenação de Aperfeiçoamento de Pessoal de Nível Superior (Brasília, DF, Br)/ This research is funded by the Conselho Nacional de Desenvolvimento Científico e Tecnológico - CNPq (Brasília, DF, Br) e pela Capes - Coordenação de Aperfeiçoamento de Pessoal de Nível Superior (Brasília, DF, Br).

Conflito de interesses/Conflict of interest: As autoras declaram que não há conflito de interesses / The authors declare that has no conflict of interest.

\section{LiLian Miranda}

Doutora em Saúde Coletiva pelo Instituto de Educação do Departamento de Psicologia da Universidade Federal Rural do Rio de Janeiro - UFRRJ. (Seropédica, RJ, Br)

Br. 465, Km.07

23890-000 Seropédica, RJ, Br

e-mail: limiranda78@hotmail.com

\section{Rosana Teresa Onocko Campos}

Doutora em Saúde Coletiva pela Faculdade de Ciências Médicas do Departamento de Saúde Coletiva da Universidade Estadual de Campinas - Unicamp (Campinas, SP, Br).

R. Tessália Vieira Camargo, 126

Cidade Universitária "Zeferino Vaz"

Caixa Postal: 6111

13083-970 Campinas, SP, Br

e-mail: rosanaoc@mpc.com.br 